\title{
Chromosome abnormalities in pupils attending ESN/M schools
}

\author{
M A LAMONT, N R DENNIS, AND M SEABRIGHT \\ Department of Child Health, Southampton General Hospital, and Wessex Regional Cytogenetics Unit, \\ Salisbury General Hospital
}

SUMMARY One hundred and sixty six children attending educationally subnormal/mild (ESN/M) schools were karyotyped as part of a project investigating the aetiology of mild mental retardation. Nine had significant chromosome abnormalities. Five of six children identified during the survey had no dysmorphic features-47,XXY (two), 48, XXYY, 46,XX 15q-, and $46, X X, t(X ; 19)$. One dysmorphic boy had a balanced translocation - 46,XY,t $(3 ; 15)$. Three were already known-47,XX+21 (two) and 46,XY, 14q+.

We suggest that routine karyotyping of children with mild mental retardation be considered.

Chromosome abnormalities are known to be an important cause of severe mental retardation. They account for over a third of all those with an IQ of $<50$, with trisomy 21 predominating. ${ }^{1}$ The contribution of chromosome abnormalities to mild mental handicap (IQ 50-70) has not been so well defined, possibly because mild mental handicap is not always readily apparent. Its expression may be limited to poor scholastic performance, with affected individuals not being easy to identify in pre- or post school years. Nevertheless, surveys of the mildly mentally handicapped have shown a higher prevalence of chromosome abnormalities than exists in the general population. ${ }^{2-4}$ Chromosome analysis in these surveys was limited to those mildly retarded children with dysmorphic features or abnormal buccal smears. We report here on chromosomal analyses of unselected children attending educationally subnormal/mild (ESN/M) schools in Southampton performed as part of a project investigating the aetiology of mild mental handicap.

In addition to routine chromosome studies we wished to ascertain the prevalence of the fragile $X$ chromosome in this group of ESN/M children. The association of the fragile $\mathrm{X}$ marker in boys with mental retardation, both severe and mild, has been recognised over the last few years. ${ }^{5-7}$ Turner found fragile $X$ chromosomes in five out of 72 mildly retarded girls with no physical abnormalities, and recommended testing for fragile $\mathrm{X}$ chromosome in mildly retarded girls.

\section{Materials and methods}

Population. ESN/M schools provide special education for children who come into the range of mild mental handicap, defined by the World Health Organisation in 1968 as IQ 50-70. Intelligence tests are usually carried out only in children who have been perceived to fail academically and are being considered for ESN/M schools. Factors other than IQ may influence referral of a child to an ESN/M school. Social adaptation, parental attitudes, and the availability of remedial teaching in the 'normal' school can all bias selection. Thus a study population of children attending ESN/M schools is unlikely to contain all school children in the IQ range 50-70, nor is it unbiased.

Within these limitations, we thought that a survey of children attending ESN/M schools was a valid project and the only practicable way to identify a study population of mildly mentally handicapped children.

Methods. Chromosome analysis was performed as part of a wider survey. Information collected for each child also included details of pre- and perinatal history and early development. A subjective assessment was made of the social conditions at home and parental ability; these were classed as superior, average, or poor.

With the written permission of parents, the children had a detailed clinical examination at 


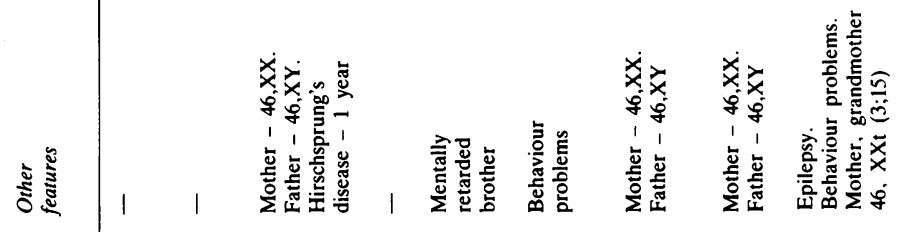

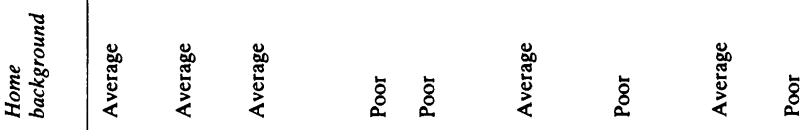

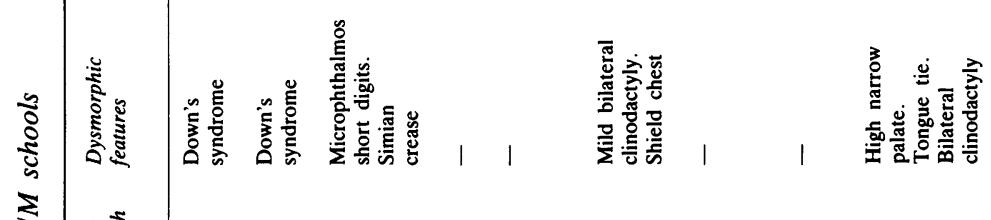

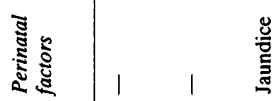

童言

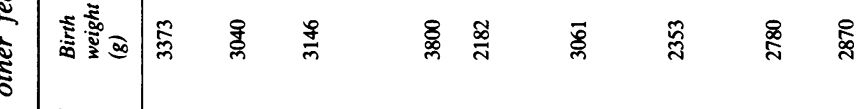


school. Blood samples were obtained and sent by first class post to the Wessex Regional Cytogenetics Unit. Cultures were set up in low folate Iscove medium and harvested at 48 or 72 hours. Thirty metaphases from $G$ banded preparations were examined from each child.

A repeat analysis was done on children karyotyped previously to screen them for the presence of the fragile $\mathrm{X}$ chromosome.

Parents' chromosomes were analysed when a possible familial abnormality was found.

\section{Results}

From a total population in Southampton of 11921 children born between August 1971 and July 1976, $229(2 \%)$ were attending ESN/M schools during the period of the survey. Parental permission for inclusion in the survey was obtained for 169 . Chromosome results are available in 166 children, 96 boys and 70 girls. In one child venepuncture was unsuccessful on two occasions. A repeat sample was not obtained in two children out of eight in whom the initial culture failed.

Nine children $(5 \%)$ had significant chromosomal abnormalities. Details are given in the Table. The two girls with Down's syndrome and a dysmorphic boy, karyotype $46, \mathrm{XY}, 14 \mathrm{q}+$, had already been identified. The girl $46, \mathrm{XX}$,del(15) had one cell with fragile $X$ in a repeat culture performed to check on the autosomal deletion. A further culture, incubated with uracil, and caffeine plus uracil, showed fragile $\mathrm{X}$ in two cells out of 225 examined.

\section{Discussion}

Children with evident dysmorphic features and developmental delay will usually be seen at an early age for paediatric assessment, which may include cytogenetic analysis. Mild developmental delay occurring in children without overt clinical features, however, is not usually considered to be an indication for chromosomal investigation. Such children may progress reasonably well in preschool years and are often referred for special education after a period in normal schools, when their difficulty in coping becomes apparent. Attention is then directed towards providing education suited to the child's needs, and, without specific indication, no detailed medical investigation is undertaken. Perinatal problems or a poor social background may be accepted as sufficient aetiology.

Of the 166 children in this survey, nine (5\%) had a major chromosome anomaly. This is a 10-fold increase over the incidence of chromosome abnormalities found, with less sophisticated cytogenetic techniques, in newborn infants. ${ }^{9}$ If we had limited chromosomal analysis in this survey to children with dysmorphic features, or to children with no adverse features in their early background, we should have failed to identify four. In five of the six children identified during the study there was no indication for chromosomal analysis other than mild mental retardation; they were not noticeably dysmorphic. In addition, four of these five had adverse factors in pregnancy, the perinatal period, or in their social background. Ironically, the one dysmorphic child-46,XY,t $(3 ; 15)$-in whom a chromosome abnormality was found had inherited the translocation from his phenotypically normal mother and maternal grandmother. It is therefore likely to be balanced and unassociated with his retardation or dysmorphic features.

Sex chromosome anomalies were found in three of the 96 boys ( $3 \%$ ): two $47, X X Y$, one $48, X X Y Y$. All three showed the speech problems commonly found in boys with sex chromosome aneuploidy. ${ }^{9}$ Sex chromosome abnormalities occur in $0.3 \%$ of newborn boys. ${ }^{10}$ The total school population of appropriate age in Southampton during the period of the survey was 11921 . Of these children, about 18 boys should have an abnormal sex chromosome complement. We identified three. A follow up study of 12 boys aged 16-18 years found to have XXY karyotypes during a neonatal screening programme reported that they had no difficulties with education until secondary school. ${ }^{11}$ It is therefore possible that problems in the early history and family background were the main factors responsible for the early referral to an ESN/M school of the two XXY boys identified in the survey.

The XXYY boy had no adverse features in his history or social environment. The mean IQ of 33 XXYY boys reviewed by Barlow was $62 \cdot 6 ;^{12}$ the retardation of our XXYY boy can be reasonably attributed to his sex chromosome aneuploidy. He had poor coordination, a short attention span, and impulsive behaviour, which are in keeping with other recorded XXYY boys. ${ }^{13}$

The girl with karyotype $46, X, t(X ; 19)$ fell within the range of borderline intelligence-IQ 74 . Mental retardation is not invariable with $\mathrm{X}$ autosome translocations but was present in six out of 66 cases reviewed. ${ }^{14}$ Despite a history of very heavy alcohol intake by her mother during pregnancy, she showed none of the physical signs of the fetal alcohol syndrome, but one cannot exclude this as a contributory factor in her retardation.

The deletion of chromosome 15 found in one child is similar to that described in association with the Prader-Willi syndrome. ${ }^{15}$ This girl had, apart from her retardation, no features of the syndrome. She 
had an Apgar score of 4 at five minutes after delivery and was in the special care nursery for a week thereafter, but there was no history of hypotonia or motor developmental delay. She was heavily built, but not unduly obese, and did not have an exceptional appetite. Schwatz reviewed 15 cases with similar deletions of 15q; while 13 of these were hypotonic, the only feature common to all was mental retardation. ${ }^{16}$ This girl's retardation is probably due, at least in part, to the chromosomal deletion.

Fragile X chromosome in one out of 166 children in this study does not reflect the prevalence of fragile $\mathrm{X}$ found in other studies of ESN/M children. Blomquist, having found the fragile $\mathrm{X}$ chromosome in five out of 110 mildly mentally retarded boys, concluded that, next to trisomy 21 , the fragile $\mathrm{X}$ syndrome is the most common single identifiable cause of mild mental retardation in boys. ${ }^{17}$ Hecht recommends that 50 cells, 10 banded, 40 unbanded, should be checked to detect the presence of fragile $\mathrm{X} .{ }^{18}$ In this study 30 cells were examined from each specimen. This may have reduced the level of detection but is a possible, rather than probable, explanation for the low prevalence of fragile $X$ in these children. The selection policies of different education authorities could affect the prevalence of certain conditions in school children receiving special education.

This study of an unselected series of 166 mildly retarded children has detected a prevalence of chromosome abnormalities of $5 \%$. Only one of these abnormalities, the balanced $(3 ; 15)$ translocation, carried a familial risk. We find, however, that a medical 'label' often helps parents to accept their child's need for special education. We would suggest that consideration be given to karyotyping all children referred to ESN/M schools.

This research was supported by a grant from Wessex Regional Health Authority. We are indebted to Hampshire Education Authority, the head teachers, staff, and parents at the schools involved in the project for their cooperation.

\section{References}

' Gustavson KH, Hagberg B, Hagberg G, Sars K. Severe mental retardation in a Swedish county. II. Etiologic and pathogenetic aspects of children born 1959-1970. Neuropediatrics 1977,8: 293-304.

2 Czeizel A, Lanyi-Engelmayer A, Klujber L, Metneki J, Tusnady G. Etiological study of mental retardation in Budapest, Hungary. Am J Ment Defic 1980;85:120-8.

3 Hagberg B, Hagberg G, Lewerth A, Lindberg U. Mild mental retardation in Swedish school children. II. Etiologic and pathogenetic aspects Acta Paediatr Scand 1981;70:445-52.

4 Einfeld SL. Clinical assessment of 4500 developmentally delayed individuals. J Ment Defic Res 1984;28:129-42.

${ }^{5}$ Blomquist HK, Gustavson KH, Holingren G, Nordenson I, Sweins A. Fragile site $\mathrm{X}$ chromosomes and $\mathrm{X}$-linked mental retardation in severely retarded boys in a northern Swedish county. A prevalence study. Clin Genet 1982;21:209-14.

${ }^{6}$ Kahkonen M, Leisti J, Wilska M, Varonen S. Marker Xassociated mental retardation. A study of 150 retarded males. Clin Genet 1983;23:397-404.

7 Turner GR, Brookwell R, Daniel A, Selikowitz M, Zilibowitz $\mathrm{M}$. Heterozygous expression of X-linked mental retardation and X-chromosome marker Fra(X) (q 27). $N$ Engl J Med 1980;303:662-4.

* Seabright M. A rapid banding technique for human chromosomes. Lancet 1971;ii:971-2.

9 Heir DB, Atkins L, Perlo VP. Learning disorders and sex chromosome aberrations. J Ment Defic Res 1980;24:17-26.

10 Jacobs PA, Melville M, Ratcliffe SG, Keay AJ, Syme J. A cytogenetic survey of 11,680 newborn infants. Ann Hum Genet 1974;37:359-76.

" Ratcliffe SG, Bancroft J, Axworthy D, McLaren W. Klinefelter's syndrome in adolescence. Arch Dis Child 1982;57:6-12.

12 Barlow $P$. The influence of inactive chromosomes on human development. Anomalous sex chromosome complements and the phenotype. Hum Genet 1973;17:105-36.

${ }^{13}$ Borgaonkar DS, Mules E, Char F. Do the 48,XXYY males have a characteristic phenotype? Clin Genet 1970;1:272-93.

14 Carpenter NJ, Sag B, Browning D. Gonodal dysgenesis in a patient with an X:3 translocation; case report and review. J Med Genet 1980;17:216-21.

15 Mattei JF, Mattei MG, Giraud F. Prader-Willi syndrome and chromosome 15. Hum Genet 1983;64:356-62.

16 Schwatz S, Max SR, Panny SR, Cohen MM. Deletions of proximal $15 \mathrm{q}$ and non-classical Prader-Willi syndrome phenotypes. American Journal of Medical Genetics 1985;20:255-63.

17 Blomquist HK, Gustavson KH, Holingren G. Fra X syndrome in mildly mentally retarded children in a northern Swedish county. A prevalence study. Clin Genet 1983;24:393-8.

${ }^{18}$ Hecht F, Sutherland GR. Detection of the fragile X chromosome and other fragile sites. Clin Genet 1984;26:301-3.

Correspondence to Dr M A Lamont, Department of Child Health, Level G Centre Block, Southampton General Hospital, Southampton SO9 $4 \mathrm{XY}$.

Received 20 November 1985 